\title{
Importância de polimorfismos de genes reguladores de citocinas em transplantes de células progenitoras hematopoiéticas
}

\author{
Jeane Eliete Laguila Visentainer ${ }^{*}$, Ana Maria Sell' ${ }^{1}$ Danilo Alessio Franceschi', \\ Sofia Rocha Lieber², Cármino Antonio de Souza ${ }^{3}$ \\ ${ }^{1}$ Departamento de Análises Clínicas, Universidade Estadual de Maringá, '2Laboratório HLA (Human Leucocyte \\ Antigens), Centro de Hematologia e Hemoterapia, Universidade Estadual de Campinas, ${ }^{3}$ Departamento de Clínica \\ Médica, Faculdade de Ciências Médicas, Universidade Estadual de Campinas
}

${ }^{*}$ Correspondência:

J. E. L. Visentainer

Departamento de Análises Clínicas

Universidade Estadual de Maringá

Av. Colombo, 5.790

87020-900 - Maringá - PR, Brasil

E-mail: jelvisentainer@uem.br;

jelvisentainer@gmail.com
A compatibilidade genética HLA entre doador e receptor é um fator importante para o sucesso do transplante de células progenitoras hematopoiéticas (TCPH). No entanto, outros genes não-HLA estão sendo investigados em relação ao seu papel na incidência e gravidade da doença do enxerto contra o hospedeiro e na sobrevida, por modularem a intensidade da inflamação e os danos teciduais. Estes genes, não-HLA, incluem os genes de citocinas com polimorfismos dentro das seqüências 5' ou 3' regulatórias dos genes. Os polimorfismos ou microssatélites podem alterar a ligação dos fatores de transcrição aos sítios dentro dos genes promotores e a quantidade de citocina produzida. Este estudo revisa o papel potencial destes polimorfismos genéticos relativos às citocinas em prever o curso do TCPH.

\section{Unitermos}

- Polimorfismo genético

- Citocinas

- Doença do enxerto contra o hospedeiro

- Células progenitoras hematopoiéticas/transplante

\section{INTRODUÇÃO}

Embora a compatibilidade HLA seja crítica para prevenir a doença do enxerto contra o hospedeiro $(\mathrm{DECH})$ em transplantes de células progenitoras hematopoiéticas (TCPH) (Petersdorf, 2006), genes não-HLA como os genes de histocompatibilidade secundários, genes KIR (do inglês, killer immunoglobulin-like receptor), genes $M I C$ (do inglês, MHC class I chain-related) e genes de regiões reguladoras de citocinas estão sendo investigados em relação ao papel na incidência e gravidade de $\mathrm{DECH}$ e na sobrevida (Randolph et al., 2004; Bignon, Gagna, 2005; Farag et al., 2006; Kitcharoen et al., 2006; Dickinson, 2007).

Os primeiros genes, não-HLA, a serem estudados foram os genes de citocinas com polimorfismos dentro de re- giões reguladoras. Esta revisão tem o objetivo de evidenciar o papel potencial de cada um destes genes de citocinas em prever o curso do TCPH e de apresentar as direções futuras no âmbito da aplicação destas genotipagens na seleção de doadores e na condução da terapia imunossupressora.

\section{Polimorfismos únicos de nucleotídeos ou microssatélites de genes de citocinas}

Polimorfismos únicos de nucleotídeos (SNPs) ou microssatélites podem alterar a ligação dos fatores de transcrição aos sítios dentro dos genes promotores e a quantidade de citocina produzida (Wilson et al., 1997; Turner et al., 1998; Awad et al., 1998; Fishman et al., 1998; Pravica et al., 1999). SNPs são variações de uma única base na seqüência de um alelo no cromossomo, enquanto 
microssatélites são seqüências repetidas de um a quatro nucleotídeos espalhadas pelo genoma (GA, CT, GT, CA), como representados nas Figuras 1 e 2, respectivamente.

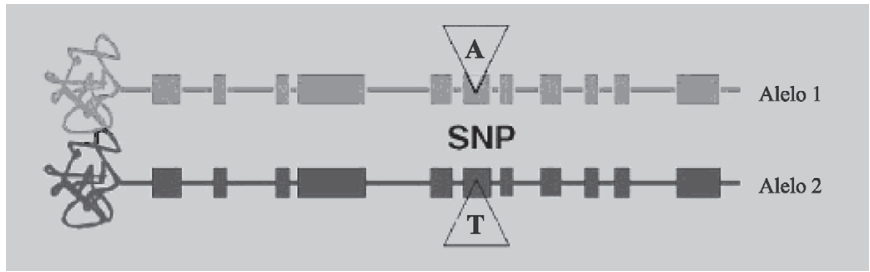

FIGURA 1 - Localização de polimorfismos únicos de nucleotídeos nos alelos 1 (A) e 2 (T) de um cromossomo.

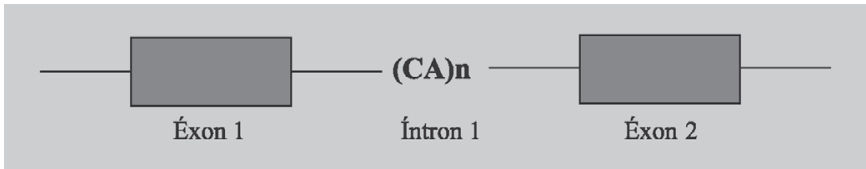

FIGURA 2 - Microssatélites localizados em regiões não codificadoras (íntron) do cromossomo.

Nos últimos anos, vários estudos mostraram que estes polimorfismos eram responsáveis pelas variações fenotípicas associadas a várias doenças (Hollegaard, Bidwel, 2006) e ao curso dos transplantes (Middleton et al. 1998; Cavet et al., 1999; Takahashi et al., 2000; Cavet et al. 2001; Leffell et al., 2001; Tambur et al., 2001; Socié et al. 2001; Dickinson et al., 2001; Nordlander et al., 2002).

\section{Citocinas envolvidas no TCPH}

Citocinas são mediadores solúveis da resposta imune produzidos durante o processo inflamatório que se inicia com o condicionamento do paciente. A imunopatogênese da $\mathrm{DECH}$ já está bem estabelecida (revisado em Vizoni et al., 2008), a qual pode ser classificada em 3 fases:

1. Fase de condicionamento: o condicionamento causa lesão nos tecidos do hospedeiro. Os lipopolissacarídeos (LPS) de bactérias contribuem para iniciar um processo inflamatório com produção de citocinas: IL-1, IL-6 e TNF- $\alpha$. Estes fatos resultam na maior expressão de moléculas do Complexo Principal de Histocompatibilidade (CPH) e de adesão nos tecidos do hospedeiro.

2. Fase de ativação de células T do doador: células T do doador reconhecem antígenos nos tecidos do hospedeiro. Estes antígenos podem ser moléculas do $\mathrm{CPH}$ ou mHA (do inglês, minor histocompatibility antigens). Nesta fase, as células Th1 proliferam na presença de IL-12 e produzem IL-2 e IFN- $\gamma$, as quais induzem expansão de células T e respostas de células T citotóxicas (CTLs) e de células Natural Killer (NK).
3. Fase efetora da inflamação: fagócitos mononucleares ativados por LPS e outros mediadores da inflamação liberam o seu conteúdo citoplasmático (IL-1, TNF- $\alpha$ e óxido nítrico), os quais podem causar lesões diretas nas células-alvo do hospedeiro. Além disso, CTLs e NK, ativadas na etapa anterior, além de liberarem TNF- $\alpha$, promovem citotoxicidade mediada por células por meio da perforina e mecanismos de Fas e Fasligante. Tais processos inflamatórios resultam em lesões dos tecidos e morte das células-alvo por apoptose.

O papel de citocinas pró e antiinflamatórias no desenvolvimento de $\mathrm{DECH}$ é complexo e dependente de variáveis envolvidas no processo do transplante, como a intensidade do regime de condicionamento, a fonte de células progenitoras, a profilaxia imunossupressora e o local de ocorrência da DECH. A produção de citocinas do tipo Th1 é característica da DECH aguda, enquanto citocinas do tipo Th2 são importantes na DECH crônica. A patogênese da DECH crônica parece envolver mecanismos de auto-imunidade. Ela inicia com a expansão de células T do doador em resposta a alo ou auto-antígenos que escapam da avaliação do timo e dos mecanismos de deleção. As células T induzem lesão nos órgãos-alvo por meio do ataque citolítico, citocinas inflamatórias e fibrose ou pela ativação das células B, com produção de auto-anticorpos (PérezSimón et al., 2006).

\section{Participação de genes de citocinas no curso do TCPH}

Estudos iniciais em TCPH mostraram associações dos polimorfismos de genes TNF e ILIO com o curso do transplante (Cavet et al., 1999; Takahashi et al., 2000). Os genótipos de alto produtor de TNF- $\alpha$ e baixo produtor de IL-10 foram relacionados ao mau prognóstico no TCPH. Estes polimorfismos podem influenciar a liberação de citocinas em diferentes estágios da DECH aguda e crônica. O genótipo do paciente pode influenciar como o regime de condicionamento afeta a liberação de citocinas pró-inflamatórias no pré-transplante; enquanto o genótipo do doador, possivelmente em adição ao genótipo do paciente, influenciará a incidência e gravidade da DECH e a mortalidade relacionada ao transplante.

A maioria dos estudos tem verificado a influência de genótipos de genes de citocinas no curso do TCPH em relação à ocorrência de $\mathrm{DECH}$ e mortalidade; enquanto a base genética de outros seguimentos, como a infecção e toxicidade por drogas, está sendo menos investigada. Atualmente, vários estudos envolvendo genes de citocinas e seus receptores vêm sendo conduzidos e podem ser visualizados na Tabela I. 
TABELA I - Estudos sobre polimorfismos únicos de nucleotídeos de genes de citocinas associados com a doença do enxerto contra o hospedeiro

\begin{tabular}{|c|c|c|}
\hline Aguda & $\overline{\mathrm{DECH}}$ & \multirow[b]{2}{*}{ Referências } \\
\hline \multicolumn{2}{|c|}{ SNP/Genótipo } & \\
\hline Ausência de $I L 1 R N^{*} 2$ & Ausência de $I L 1 R N^{*} 2$ & Rocha et al. (2002) \\
\hline$I L 1 R N^{*} 2$ & & Cullup et al. (2001) \\
\hline & $I L 1 A^{-889 * 2}$ & Cullup et al. (2003) \\
\hline$I L 6^{-174} \mathrm{G} / \mathrm{C}$ & $I L 6^{-174} \mathrm{GG}$ & Cavet et al. (2001), Lin et al. (2003) \\
\hline & $I L 6^{-174} \mathrm{G} / \mathrm{C}$ & Socié et al. (2001) \\
\hline & $I L 6^{-174} \mathrm{CC}$ & Laguila Visentainer et al. (2005) \\
\hline$T N F^{-308} \mathrm{GG} / \mathrm{GA}$ & & Takahashi et al. (2000) \\
\hline$T N F d 4$ & & Nordlander et al. (2002) \\
\hline & $T N F^{-238} \mathrm{GA}$ & Viel et al. (2007) \\
\hline$I F N G^{+874} \mathrm{AA}$ & & Cavet et al. (2001) \\
\hline IFNG íntron $2 / 2$ & & Mlynarczewska et al. (2004) \\
\hline$I L 2^{-330} \mathrm{GT}$ & & Macmillan et al. (2003b) \\
\hline IL 10 $0^{-1082,-819,-592} \mathrm{GCC} / \mathrm{GCC}$ & & Dickinson et al. (2001), Socié et al. (2001) \\
\hline & IL $10^{-1082,-819,-592} \mathrm{ATA} / \mathrm{ATA}$ & Kim et al. (2005) \\
\hline & IL $10^{-1082} \mathrm{G} / \mathrm{G}$ & Rocha et al. (2002) \\
\hline$I L 10^{-592} \mathrm{~A} / \mathrm{A}$ & & Lin et al. (2003) \\
\hline$T G F B 1^{+869,+915} \mathrm{TG} / \mathrm{GG}$ & & Leffell et al. (2001) \\
\hline$T G F B 1^{+869} \mathrm{~T}$ & & Hattori et al. (2002) \\
\hline
\end{tabular}

$\mathrm{DECH}$, doença do enxerto contra o hospedeiro; SNP, polimorfismo único de nucleotídeo.

\section{Gene $T N F$}

O gene TNF está localizado no cromossomo 6, dentro da região de classe III do $\mathrm{CPH}$, próximo às regiões HLA de classe I e II e a genes envolvendo a linfotoxina alfa e beta e a proteína de choque térmico HSP70.

Alguns estudos demonstraram associações de polimorfismos deste gene com complicações tóxicas e mortalidade pós-transplante (Bogunia-Kubik et al., 2003; Bettens et al., 2006) e resultados conflitantes com DECH (Takahashi et al., 2000; Nordlander et al., 2002; Laguila Visentainer et al., 2005; Viel et al., 2007). Os primeiros estudos apontaram este polimorfismo como importante no desenvolvimento de $\mathrm{DECH}$, mas este resultado não pôde ser confirmado em estudos com número maior de pacientes (Cavet et al., 1999; Laguila Visentainer et al., 2005). Contudo, este polimorfismo tem sido associado com complicações tóxicas em transplantes HLA-idênticos aparentados ou não (Bogunia-Kubik et al., 2003). A maior incidência de complicações tóxicas foi vista em pacientes heterozigotos para $T N F A^{*} 2$ (alelo $\mathrm{A}$ ) associado à alta produção de TNF- $\alpha$. Em pacientes que receberam transplantes de indivíduos HLA-idênticos não-aparentados, foi demonstrado forte desequilíbrio de ligação entre o polimorfismo do gene TNFA-
308 e a pega tardia de neutrófilos (Shaw et al., 2004). Outros estudos também descreveram associação de $T N F+488 \mathrm{~A}$ com a forma mais grave de DECH aguda e DECH crônica e com a mortalidade precoce (Mullighan, Bardy, 2004), enquanto outros mostraram associações entre $T N F-863$ (C/A) e -857 (C/T) com DECH de grau III-IV e uma menor recaída (Ishikawa et al., 2002).

Microssatélites da região do $T N F$ também foram avaliados no curso do TCPH. A homozigose $T N F \mathrm{~d} 3 / \mathrm{d} 3$ foi associada à maior freqüência de $\mathrm{DECH}$ (Middleton et al., 1998), à mortalidade precoce (Cavet et al., 1999; Cavet et al., 2001) e à diminuição da sobrevida (Bettens et al., 2006). $\mathrm{O}$ alelo TNFd4 correlacionou-se com a mortalidade relacionada ao transplante em pacientes HLA-idênticos não-aparentados (Keen et al., 2004). O mesmo alelo TNFd4 foi também associado com moderada à grave $\mathrm{DECH}$ em transplantes HLA-idênticos não-aparentados (Nordlander et al., 2002) $\mathrm{e}$, mais recentemente, Bettens et al. (2006) mostraram que os genótipos $T N F \mathrm{~d} 3 / \mathrm{d} 3$ e $T N F \mathrm{~d} 4$ foram relacionados à menor sobrevida de pacientes HLA-idênticos não-aparentados, quando comparados aos genótipos $T N F \mathrm{~d} 1$, d2 e d3.

Numa população brasileira, nosso grupo verificou maior freqüência do genótipo $T N F-238 \mathrm{GA}$ em pacientes com DECH crônica, especificamente naqueles com a for- 
ma extensa (Viel et al., 2007), entretanto o mesmo não foi observado para a DECH aguda, o que está de acordo com Mullighan et al. (2004).

\section{Gene IL10}

O gene da IL10 está localizado no cromossomo 1 e é altamente polimórfico, com 5 SNPs e vários VNTRs ou microssatélites, resultando em vários haplótipos conservados. Estes haplótipos entre - 1082 e -592 representam alelos alto, intermediário e baixo produtores de IL-10. Vários estudos mostraram associação entre estes polimorfismos e a ocorrência ou proteção à DECH (Dickinson et al., 2001; Lin et al., 2003; Mullighan et al., 2004; Kim et al., 2005).

No início, alguns estudos mostraram associação do polimorfismo IL10-1064 de maior comprimento (12 a 15), com o aumento de DECH aguda mais grave e $\mathrm{DECH}$ crônica e com a diminuição da sobrevida em TCPH (Middleton et al., 1998; Cavet et al., 1999; Takahashi et al., 2000; Cavet et al., 2001; Nordlander et al., 2002; Bettens et al., 2006). Outros descreveram a influência de genótipos de IL101082G/G na ocorrência de DECH aguda (Kim et al., 2005) ou crônica (Rocha et al., 2002) e de haplótipos de IL10$1082,-592,-819 \mathrm{GCC} / \mathrm{GCC}$ com a maior incidência de DECH aguda (Socié et al., 2001) ou com a mortalidade relacionada ao transplante (Keen et al., 2004).

Um estudo com grande número de pacientes aparentados identificou o genótipo IL10-592*A/A (alto produtor de IL-10) como um marcador para a incidência menor de DECH graus III-IV e morte em remissão (Lin et al., 2003). Contudo, este genótipo, inserido no haplótipo IL10 (-1082/ -819/-592)*ATA, tem sido associado com risco aumentado de DECH crônica, embora em pacientes de diferentes origens étnicas (Kim et al., 2005).

\section{Gene IL6}

Neste gene, localizado no cromossomo 7, o polimorfismo $\mathrm{G} / \mathrm{C}$ na posição -174 foi associado à maior ou menor produção de IL-6. O alelo G do gene da IL6-174 foi associado à ocorrência de DECH aguda (Cavet et al., 2001), enquanto os genótipos GG e GC foram relacionados à maior probabilidade de $\mathrm{DECH}$ crônica, respectivamente (Lin et al., 2003; Socié et al., 2001).

No Brasil, os resultados foram discordantes, Laguila Visentainer et al. (2005) não observaram associação entre este polimorfismo do gene da IL6 e DECH aguda, mas encontraram maior freqüência do genótipo IL6-174CC no grupo com DECH crônica. Embora, os genótipos de IL6-174GG e GC tenham sido, anteriormente, associados aos fenótipos de alta produção desta citocina (Fishman et al.,
1998), a sua participação na patogênese da DECH crônica ainda é desconhecida. Suas propriedades antiinflamatória e imunossupressora, além da conhecida propriedade pró-inflamatória, estão sendo discutidas (Tilg et al., 1997; Diehl, Rincon, 2002). Além disso, devemos cuidar ao compararmos resultados de populações muito distintas, pois as freqüências alélicas de genes de citocinas são muito influenciadas pela diversidade étnica (Cox et al., 2001; Zhai et al., 2001; Meenagh et al., 2002; Lim et al., 2002; Uboldi De Capei et al., 2003; Trejaut et al., 2004; Gadelha et al., 2005; Kurzawski et al., 2005; Tsuneto et al., 2005).

\section{Gene IL1}

O complexo gene da $I L 1$ codifica para três proteínas: IL-1a, IL-1b e antagonista do receptor de IL-1 (IL-1RA); sendo os dois primeiros, fortes mediadores da inflamação, enquanto o IL-1RA se liga ao receptor da IL-1 sem ativar as células-alvo, atuando como um efetivo antagonista (Dinarello, 1996). Ele está localizado em uma região do cromossomo 2 humano e possui vários polimorfismos. Para a IL-1a ocorre uma troca de base na posição -889 da região promotora (Dominici et al., 2002). Dominici et al., (2002) relataram que células mononucleares estimuladas com lipopolissacarídeos (LPS) de indivíduos IL1A-889 TT aumentaram a produção de proteínas e que a atividade promotora de $I L 1 A$ é maior naqueles indivíduos com genótipo TT-889. Além disso, Santtila et al. (1998) sugeriram que o alelo $I L 1 R N^{*} 2$ estaria associado ao aumento da produção da IL-1b. Alguns microssatélites do gene IL1 como ILIRN, ILIA889 e IL1AVNTR foram relacionados à ocorrência de DECH aguda e crônica (Rocha et al., 2002; Cullup et al., 2001) e à sobrevida após o transplante (Macmillan et al., 2003a).

\section{Gene INFG}

Este gene se encontra no cromossomo $12 \mathrm{q} 24.1 \mathrm{e}$ possui 4 exóns e um elemento regulador dentro do primeiro íntron. Existem vários resultados conflitantes em relação ao gene do $I F N G$ e sua influência na ocorrência de DECH. Alguns estudos descreveram associações entre alelos de microssatélites de $I F N G$ e a DECH aguda (Cavet et al., 2001; Mlynarczewska et al., 2004). Considerando que existe correlação entre os alelos $I F N G+874$ e microssatélites dentro do primeiro íntron deste gene (Pravica et al., 1999; Mlynarczewska et al., 2004), algumas associações entre SNPs de $I F N G$ e o risco de DECH aguda seriam esperadas. Contudo, uma direta associação entre estes alelos de $I F N G+874$ e o risco de DECH aguda não foi reportada (Laguila Visentainer et al., 2005). 


\section{Gene IL2}

O gene IL2 está localizado no cromossomo 4, e dois SNPs, um na posição -330 e outro na posição +166, foram descritos por John et al. (1998). O SNP, na posição -330, foi reportado por resultar num aumento de três vezes na produção de IL-2 em indivíduos homozigotos $\mathrm{G} \backslash \mathrm{G}$ quando comparados aos homozigotos $\mathrm{T} \backslash \mathrm{T}$ (Hoffmann et al., 2001). O polimorfismo +166 é uma mutação silenciosa, a qual não afeta a seqüência de aminoácidos.

Embora MacMillan et al. (2003b) tenham mostrado que a probabilidade de DECH aguda de grau II-IV foi afetada pela presença do alelo IL2-330 G em uma população de Minnesota (USA), não foi encontrada nenhuma associação significativa com as formas da doença em nossa população brasileira (Viel et al., 2007).

\section{Gene TGFB1}

Polimorfismos do gene $T G F B 1$, encontrados no cromossomo 19 , nas posições +869 e +915 foram associados com a produção desta citocina (Awad et al., 1998). O polimorfismo na posição +869 representa troca de um resíduo de aminoácido leucina por prolina no códon 10 , enquanto o polimorfismo na posição +915 representa troca de um resíduo de aminoácido arginina por prolina no códon 25 .

A literatura mostrou resultados conflitantes entre estes polimorfismos e a ocorrência de DECH. Substituições de aminoácidos nos códons 10 e 25 , referentes à alta expressão de TGF-b1 foram associadas à maior incidência de DECH aguda em alguns estudos (Leffell et al., 2001; Hattori et al., 2002), enquanto outros relataram que $92 \%$ dos indivíduos com alta capacidade de expressão desta citocina não desenvolveram a doença (Tambur et al., 2001). Alguns, ainda, não puderam mostrar uma correlação genética destes polimorfismos com a DECH ou rejeição (Laguila Visentainer et al., 2005).

\section{Gene do receptor da IL-7 e gene IL18}

Mais recentemente, o polimorfismo do gene do receptor da IL-7 (IL7Ra-1237A/G), encontrado no cromossomo 5 , foi associado ao aumento da mortalidade em TCPH (Shamim et al., 2006). Três polimorfismos identificados no gene $I L 18$, no cromossomo 11, nas posições 137, 607 e 656, geram os haplótipos GCG, CAT e GAT; destes, o haplótipo GCG foi associado à diminuição do risco de mortalidade relacionada ao transplante (Cardoso et al., 2004).

A IL-18 é uma citocina pró-inflamatória predominantemente secretada por monócitos/macrófagos ativados
(Okamura et al., 1995; Ushio et al. 1996). Ela induz a diferenciação de linfócitos Th1 e a secreção de citocinas, tais como TNF- $\alpha$, IFN-g e IL-1b na presença de IL-12 (Micallef et al., 1996; Puren et al., 1998; Dinarello, 1999; Tominaga et al., 2000).

\section{Problemas e soluções em relação ao estudo de genes não-HLA}

O principal problema inerente de estudos de genes nãoHLA em diversas populações é a diferença nas freqüências de alelos entre grupos étnicos, especialmente entre populações homogêneas e heterogêneas, como as populações da Europa, Japão, Estados Unidos e Brasil. Populações brasileiras compreendem grupos geneticamente heterogêneos, formados principalmente por imigrantes europeus misturados com indígenas nativos e escravos africanos (CarvalhoSilva et al., 2001). Portanto, devido à diversidade étnica, há possibilidade de encontrarmos diferenças alélicas nestes genes, como confirmado por estudos realizados em várias partes do mundo (Meenagh et al., 2002; Lim et al., 2002; Uboldi De Capei et al., 2003; Trejaut et al., 2004; Gadelha et al., 2005; Kurzawski et al., 2005; Tsuneto et al., 2005; Manchanda et al., 2005; Kaur et al., 2007).

Desta forma, estudos envolvendo genes de citocinas devem ser realizados por meio de estudos retrospectivos ou prospectivos, sendo estes os mais recomendados já que permitem eliminar possíveis erros de seleção dos pacientes. Os grupos podem ser selecionados quanto ao tipo de transplante realizado, tipo de doença, profilaxia imunossupressora e tratamento da $\mathrm{DECH}$, além de outros fatores que poderiam confundir a análise. Uma colaboração multicêntrica no Brasil, envolvendo várias etnias de diferentes regiões, seria necessária para se alcançar o número de casos para aumentar o poder de futuros estudos.

\section{PERSPECTIVAS FUTURAS}

Índices de risco de DECH e de sobrevida têm sido usados clinicamente, especialmente para predizer o curso do TCPH em pacientes com LMC (Gratwohl et al., 1998; Gratwohl et al., 2002), mas eles são baseados em fatores, tais como a idade, sexo, fonte de células, tipo de profilaxia da $\mathrm{DECH}$, tempo entre o diagnóstico e o transplante e ocorrência de $\mathrm{DECH}$ e sua gravidade.

Nós estamos entrando numa era em que a informação genômica HLA detalhada e não-HLA pode ser usada para melhorar o curso do TCPH. A genotipagem de genes nãoHLA poderá refinar a seleção do doador, identificar receptores com alto risco de DECH e modificar as estratégias imunossupressoras. Ela também poderá ser usada para guiar 
o uso de novas terapias, como bloqueadores de citocinas.

Após estudos com grupos grandes e homogêneos de indivíduos, examinando vários genes não-HLA, talvez seja possível estabelecer um modelo de riscos que possa informar sobre as práticas do transplante. Nós propomos que estes estudos englobem novos dados e que envolvam transplantes mielo e não-mieloablativos, HLA-idênticos aparentados ou não e aqueles realizados com células progenitoras do sangue periférico e da medula óssea.

\section{ABSTRACT \\ Importance of regulatory cytokine gene polymorphisms in hematopoietic stem cell transplantation}

HLA genetic matching of donor and recipient is an important requirement for optimizing outcome following hematopoietic stem cell transplantation (HSCT). However, other non-HLA genes are being investigated for their role in graft-versus-host disease incidence and severity and in survival, by modulating the intensity of inflammation and tissue injury. These non-HLA-encoded genes include cytokine genes with polymorphisms within the 5' or 3' regulatory sequences of the genes. The polymorphisms or microsatellites may alter the transcription factor binding sites within the gene promoters and the amount of cytokine produced. This chapter summarizes the potential role of these genetic polymorphisms regarding the cytokines in predicting outcome of HSCT.

UNITERMS: Genetic polymorphisms. Cytokines. Graftversus-host disease. Hematopoietic stem cell/ transplantation.

\section{REFERÊNCIAS BIBLIOGRÁFICAS}

AWAD, M.R.; EL-GAMEL, A.; HASLETON, P.; TURNER, D.M.; SINNOTT, P.J.; HUTCHINSON, I.V. Genotypic variation in the transforming growth factorb1 gene. Transplantation, v.66, p.1014-1020, 1998.

BETTENS, F.; PASSWEG, J.; GRATWOHL, A.; CHALANDON, Y.; HELG C.; CHAPUIS, B.; SCHANZ, U.; LIBURA, J.; ROOSNEK, E.; TIERCY, J.M. Association of TNFd and IL-10 polymorphisms with mortality in unrelated hematopoietic stem cell transplantation. Transplantation, v.81, p.1261-1267, 2006.

BIGNON, J.D.; GAGNE, K. KIR matching in hematopoietic stem cell transplantation. Cur. Opin. Immunol., v.17, p.553-555, 2005.
BOGUNIA-KUBIK, K.; POLAK, M.; LANGE, A. TNF polymorphisms are associated with toxic but not with GVHD complications in the recipients of allogeneic sibling haematopoietic stem cell transplantation. Bone Marrow Transplant., v.3, p.617-622, 2003.

CARDOSO, S.M.; DEFOR, T.E.; TILLEY, L.A.; BIDWELL, J.L.; WEISDORF, D.J.; MACMILLAN, M.L. Patient interleukin-18 GCG haplotype associates with improved survival and decreased transplant-related mortality after unrelated-donor bone marrow transplantation. Br. J. Haematol., v.126, p.704-710, 2004.

CARVALHO-SILVA, D.R.; SANTOS, F.R.; ROCHA, J.; PENA, S.D. The phylogeography of Brazilian Y-chromosome lineages. Am. J. Hum. Genet., v.68, p.281-286, 2001.

CAVET, J.; DICKINSON, A.M.; NORDEN, J.; TAYLOR, P.R.; JACKSON, G.H.; MIDDLETON, P.G. IFN-g and interleukin-6 gene polymorphisms associate with graftversus-host disease in HLA-matched sibling bone marrow transplantation. Blood, v.98, p.1594-1600, 2001.

CAVET, J.; MIDDLETON, P.G.; SEGALL, M.; NOREEN, H.; DAVIES S.M.; DICKINSON, A.M. Recipient tumor necrosis factor-a and interleukin-10 gene polymorphisms associate with early mortality and acute graft-versus-host disease severity in HLA-matched sibling bone marrow transplants. Blood, v.94, p.3941-3946, 1999.

COX, E.D.; HOFFMANN, S.C.; DIMERCURIO, B.S.; WESLEY, R.A.; HARLAN, D.M.; KIRK, A.D.; BLAIR, P.J. Cytokine polymorphic analyses indicate ethnic differences in the allelic distribution of interleukin2 and interleukin-6. Transplantation, v.72, p.720-726, 2001.

CULLUP, H.; DICKINSON, A.M.; CAVET, J.; JACKSON, G.H.; MIDDLETON, P.G. Polymorphisms of interleukin1alpha constitute independent risk factors for chronic graft-versus-host disease after allogeneic bone marrow transplantation. Br. J. Haematol., v.122, p.778-787, 2003.

CULLUP, H.; DICKINSON, A.M.; JACKSON, G.H.; TAYLOR, P.R.; CAVET, J.; MIDDLETON, P.G. Donor interleukin 1 receptor antagonist genotype associated with acute graft-versus-host disease in human leukocyte antigen-matched sibling allogeneic transplants. $B r . J$. Haematol., v.113, p.807-813, 2001. 
DICKINSON, A.M. Risk assessment in haematopoietic stem cell transplantation: Pre-transplant patient and donor factors: non-HLA genetics. Best. Pract. Res. Clin. Haematol., v.20, p.189-207, 2007.

DICKINSON, A.M.; CAVET, J.; CULLUP, H.; WANG, X.N.; SVILAND, L.; MIDDLETON, P.G. GvHD risk assessment in hematopoietic stem cell transplantation: role of cytokine gene polymorphisms and an in vitro human skin explant model. Hum. Immunol., v.62, p.1266-1276, 2001.

DIEHL, S.; RINCON, M. The two faces of IL-6 on Th1/Th2 differentiation. Mol. Immunol., v.39, p.531-536, 2002.

DINARELLO, C.A. IL-18: a TH1-inducing, proinflammatory cytokine and new member of the IL-1 family. J. Allergy Clin. Immunol., v.103, p.11-24, 1999.

DINARELLO, C.A. Biologic bases for Interleukin-1 in disease. Blood, v.87, p.2095-2147, 1996.

DOMINICI, R.; CATTANEO, M.; MALFERRARI, G.; ARCHI, D.; MARIANI, C.; GRIMALDI, L.M.; BIUNNO, I. Cloning and functional analysis of the allelic polymorphism in the transcription regulatory region of interleukin-1 alpha. Immunogenetics, v.54, p.82-86, 2002.

FARAG, S.S.; BACIGALUPO, A.; EAPEN, M.; HURLEY, C.; DUPONT, B.; CALIGIURI, M.A.; BOUDREAU, C.; NELSON, G.; OUDSHOORN, M.; VAN ROOD, J.; VELARDI, A.; MAIERS, M.; SETTERHOLM, M.; CONFER, D.; POSCH, P.E.; ANASETTI, C.; KAMANI, N.; MILLER, J.S.; WEISDORF, D.; DAVIES, S.M. The Effect of KIR Ligand Incompatibility on the Outcome of Unrelated Donor Transplantation: A Report from the Center for International Blood and Marrow Transplant Research, the European Blood and Marrow Transplant Registry, and the Dutch Registry. Biol. Blood Marrow Transplant., v.12, p.876-884, 2006.

FISHMAN, D.; FAULDS, G.; JEFFERY, R.; MOHAMEDALI, V.; YUDKIN, J.S.; HUMPHRIES, S.; WOO, P. The effect of novel polymorphisms in the interleukin-6 (IL-6) gene on IL-6 transcription and plasma IL-6 levels, and an association with systemic-onset juvenile chronic arthritis. J. Clin. Invest., v.102, p.1369-1376, 1998.
GADELHA, S.R.; ALCANTARA, L.C.; COSTA, G.C.; RIOS, D.L.; GALVÃO-CASTRO, B. Ethnic differences in the distribution of interleukin-6 polymorphisms among three Brazilian ethnic groups. Hum. Biol., v.77, p.509514, 2005.

GRATWOHL, A.; BRAND, R.; APPERLEY, J.; BIEZEN, A.V.A.; BANDINI, G.; DEVERGIE, A.; SCHATTENBERG, A.; FRASSONI, F.; GUGLIELMI, C.; IACOBELLI, S.; MICHALLET, M.; KOLB, H.J.; RUUTU, T.; NIEDERWIESER, D. Graft-versus-host disease and outcome in transplantations for chronic myeloid leukemia. Blood, v.100, p.3877-3886, 2002.

GRATWOHL, A.; HERMANS, J.; GOLDMAN, J.M.; ARCESE, W.; CARRERAS, E.; DEVERGIE, A.; FRASSONI, F.; GAHRTON, G.; KOLB, H.J.; NIEDERWIESER, D.; RUUTU, T.; VERNANT, J.P.; DE WITTE, T.; APPERLEY, J. Risk assessment for patients with chronic before allogeneic blood or marrow transplantation. Chronic Leukemia Working Group for Blood and Marrow Transplantation. Lancet, v.352, p.1087-1092, 1998.

HATTORI, H.; MATSUZAKI, A.; SUMINOE, A.; IHARA, K.; NAGATOSHI, Y.; SAKATA, N.; KAWA, K.; OKAMURA, J.; HARA, T. Polymorphisms of transforming growth factor-beta 1 and transforming growth factor-beta1 type II receptor genes are associated with acute graft-versus-host disease in children with HLAmatched sibling bone marrow transplantation. Bone Marrow Transplant., v.30, n.10, p.665-671, 2002.

HOFFMANN, S.C.; STANLEY, E.M.; DARRIN COX, E.; CRAIGHEAD, N.; DIMERCURIO, B.S.; KOZIOL, D.E.; HARLAN, D.M.; KIRK, A.D.; BLAIR, P.J. Association of cytokine polymorphic inheritance and in vitro cytokine production in anti-CD3/CD28-stimulated peripheral blood lymphocytes. Transplantation, v.2, p.1444-1450, 2001.

HOLLEGAARD, M.V.; BIDWELL, J.L. Cytokine gene polymorphism in human disease: on-line databases, Supplement 3. Genes Immun., v.7, p.269-276, 2006.

ISHIKAWA, Y.; KASHIWASE, K.; AKAZA, T.; MORISHIMA, Y.; INOKO, H.; SASAZUKI, T.; KODERA, Y.; JUJI, T. Polymorphisms in TNFA and TNFR2 affect outcome of unrelated bone marrow transplantation. Bone Marrow Transplant., v.29, p.569$575,2002$. 
JOHN, S.; TURNER, D.; DONN, R.; SINNOTT, P.; WORTHINGTON, J.; OLLIER, W.E.; HUTCHINSON, I.V.; HAJEER, A.H. Two novel biallelic polymorphisms in the IL-2 gene. Eur. J. Immunogenet., v.25, p.419-420, 1998 .

KAUR, G.; RAPTHAP, C.C.; KUMAR, N.; KUMAR, S.; NEOLIA, S.; MEHRA, N.K. Frequency distribution of cytokine gene polymorphisms in the healthy North Indian population. Tissue Antigens, v.69, p.113-120, 2007.

KEEN, L.J.; DEFOR, T.E.; BIDWELL, J.L.; DAVIES, S.M.; BRADLEY, B.A.; HOWS, J.M. Interleukin-10 and tumor necrosis factor alpha region haplotypes predict transplantrelated mortality after unrelated donor stem cell transplantation. Blood, v.103, p.3599-3602, 2004.

KIM, D.H.; LEE, N.Y.; SOHN, S.K.; BAEK, J.H., KIM, J.G., SUH, J.S.; LEE, K.B.; SHIN, I.H. IL-10 promoter gene polymorphism associated with the occurrence of chronic GVHD and its clinical course during systemic immunosuppressive treatment for chronic GVHD after allogeneic peripheral blood stem cell transplantation. Transplantation, v.79, p.1615-1622, 2005.

KITCHAROEN, K.; WITT, C.S.; ROMPHRUK, A.V.; CHRISTIANSEN, F.T.; LEELAYUWAT, C. MICA, MICB, and MHC Beta Block Matching in Bone Marrow Transplantation: Relevance to Transplantation Outcome. Hum. Immunol., v.67, p.238-246, 2006.

KURZAWSKI, M.; PAWLIK, A.; CZERNY, B.; DOMACœKI, L.; RÓZACœKI, J.; DROyDZIK, M. Frequencies of the common promoter polymorphisms in cytokine genes in a Polish population. Int. J. Immunogenet., v.32, p.285-291, 2005.

LAGUILA VISENTAINER, J.E.; LIEBER, S.R.; PERSOLI, L.B.; DUTRA MARQUES, S.B.; VIGORITO, A.C.; PENTEADO ARANHA, F.J.; DE BRITO EID, K.A.; OLIVEIRA, G.B.; MARTINS MIRANDA, E.C.; BRAGOTTO, L.; DE SOUZA, C.A. Relationship between cytokine gene polymorphisms and graft-versushost disease after allogeneic stem cell transplantation in a Brazilian population. Cytokine, v.32, p.171-177, 2005.

LEFFELL, M.S.; VOGELSANG, G.B.; LUCAS, D.P.; DELANEY, N.L.; ZACHARY,A.A.Association between TGF-b expression and severe GVHD in allogeneic bone marrow transplantation. Transplant. Proc., v.33, p.485486, 2001.
LIM, C.S.; ZHENG, S.; KIM, Y.S.; AHN, C.; HAN, J.S.; KIM, S.; LEE, J.S.; CHAE, D.W. The -174 G to C polymorphism of interleukin-6 gene is very rare in Koreans. Cytokine, v.19, p.52-54, 2002.

LIN, M.T.; STORER, B.; MARTIN, P.J.; TSENG, L.H.; GOOLEY, T.; CHEN, P.J.; HANSEN, J.A. Relation of an interleukin-10 promoter polymorphism to graft-versushost disease and survival after hematopoietic-cell transplantation. N. Engl. J. Med., v.349, p.2201-2210, 2003.

MACMILLAN, M.L.; RADLOFF, G.A.; DEFOR, T.E.; WEISDORF, D.J.; DAVIES, S.M. Interleukin-1 genotype and outcome of unrelated donor bone marrow transplantation. Br. J. Haematol., v.121, p.597-604, 2003a.

MACMILLAN, M.L.; RADLOFF, G.A.; KIFFMEYER, W.R.; DEFOR, T.E.; WEISDORF, D.J.; DAVIES, S.M. High-producer interleukin-2 genotype increases risk for acute graft-versus-host disease after unrelated donor bone marrow transplantation. Transplantation, v.76, p.1758$1762,2003 b$.

MANCHANDA, P.K.; BID, H.K.; MITTAL, R.D. Ethnicity greatly influences the interleukin-1 gene cluster (IL-1 ${ }^{2}$ Promoter, Exon-5 and IL-1Ra) polymorphisms: A pilot study of a North Indian population. Asian Pac. J. Cancer Prev., v.6, p.541-546, 2005.

MEENAGH, A.; WILLIAMS, F.; ROSS, O.A.; PATTERSON, C.; GORODEZKY, C.; HAMMOND, M.; LEHENY, W.A.; MIDDLETON, D. Frequency of cytokine polymorphisms in populations from Western Europe, Africa, Asia, the Middle East and South America. Hum. Immunol., v.63, p.1055-1061, 2002.

MICALLEF, M.J.; OHTSUKI, T.; KOHNO, K.; TANABE, F.; USHIO, S.; NAMBA, M.; TANIMOTO, T.; TORIGOE, K.; FUJII, M.; IKEDA, M.; FUKUDA, S.; KURIMOTO, M. Interferon-gamma-inducing factor enhances T helper 1 cytokine production by stimulated human T cells: synergism with interleukin-12 for interferon-gamma production. Eur. J. Immunol., v.26, p.1647-1651, 1996.

MIDDLETON, P.G.; TAYLOR, P.R.; JACKSON, G.; PROCTOR, S.J.; DICKINSON, A.M. Cytokine gene polymorphisms associating with severe acute graftversus-host disease in HLA-identical sibling transplants. Blood, v.92, p.3943-3948, 1998. 
MLYNARCZEWSKA, A.; WYSOCZANSKA, B.; KARABON, L.; BOGUNIA-KUBIK, K.; LANGE, A. Lack of IFN-gamma 2/2 homozygous genotype independently of recipient age and intensity of conditioning regimen influences the risk of aGVHD manifestation after HLA-matched sibling haematopoietic stem cell transplantation. Bone Marrow Transplant., v.34, p.339344, 2004.

MULLIGHAN, C.G.; BARDY, P.G. Advances in the genomics of allogeneic haemopoietic stem cell transplantation. Drug Dev. Res., v.62, p.273-292, 2004.

MULlighAN, C.; HEATLEY, S.; DOHERTY, K.; SZABO, F.; GRIGG, A.; HUGHES, T.; SCHWARER, A.; SZER, J.; TAIT, B.; TO, B.; BARDY, P. Non-HLA immunogenetic polymorphisms and the risk of complications after allogeneic hemopoietic stem-cell transplantation. Transplantation, v.77, p.587-596, 2004.

NORDLANDER, A.; UZUNEL, M.; MATTSSON, J.; REMBERGER, M. The TNFd4 allele is correlated to moderate-to-severe acute graft-versus-host disease after allogeneic stem cell transplantation. Br. J. Haematol., v.119, p.1133-1136, 2002.

OKAMURA, H.; TSUTSI, H.; KOMATSU, T.; YUTSUDO, M.; HAKURA, A.; TANIMOTO, T.; TORIGOE, K.; OKURA, T.; NUKADA, Y.; HATTORI, K. Cloning of a new cytokine that induces IFN-gamma production by $\mathrm{T}$ cells. Nature, v.378, p.88-91, 1995.

PÉREZ-SIMÓN, J.A.; SÁNCHEZ-ABARCA, I.; DÍEZCAMPELO, M.; CABALLERO, D.; SAN MIGUEL, J. Chronic Graft-Versus-Host Disease Pathogenesis and Clinical Management. Drugs, v.66, p.1041-1057, 2006.

PETERSDORF, E.W. Immunogenomics of unrelated hematopoietic cell transplantation. Cur. Opin. Immunol., v.18, p.559-564, 2006.

PRAVICA, V.; ASDERAKIS, A.; PERREY, C.; HAJEER, A.; SINNOTT, P.J.; HUTCHINSON, I.V. In vitro production of IFN-gamma correlates with CA repeat polymorphism in the human IFN-gamma gene. Eur. $J$. Immunogenet., v.26, p.1-3, 1999.

PUREN, A.J.; FANTUZZI, G.; GU, Y.; SU, M.S.; DINARELLO, C.A. Interleukin-18 (IFNgammainducing factor) induces IL-8 and IL-1 beta via TNFalpha production from non-CD14+ human blood mononuclear cells. J. Clin. Invest., v.101, p.711-721, 1998.
RANDOLPH, S.S.; GOOLEY, T.A.; WARREN, E.H.; APPELBAUM, F.R.; RIDDELL, S.R. Female donors contribute to a selective graft-versus-leukemia effect in male recipients of HLA-matched, related hematopoietic stem cell transplants. Blood, v.103, p.347-352, 2004.

ROCHA, V.; FRANCO, R.F.; PORCHER, R.; BITTENCOURT, H.; SILVA, W.A. Jr.; LATOUCHE, A.; DEVERGIE, A.; ESPEROU, H.; RIBAUD, P.; SOCIE, G.; ZAGO, M.A.; GLUCKMAN, E. Host defense and inflammatory gene polymorphisms are associated with outcomes after HLA-identical sibling bone marrow transplantation. Blood, v.100, p.3908-3918, 2002.

SANTTILA, S.; SAVINAINEN, K.; HURME, M. Presence of the IL1-RA allele 2 (IL1RN*2) is associated with enhanced IL-1b production in vitro. Scand. J. Immunol., v.47, p.145-198, 1998.

SHAMIM, Z.; RYDER, L.P.; HEILMANN, C.; MADSEN, H.; LAUERSEN, H.; ANDERSEN, P.K.; SVEJGAARD, A.; JACOBSEN, N.; MÜLLER, K. Genetic polymorphisms in the genes encoding human interleukin-7 receptor-alpha: prognostic significance in allogeneic stem cell transplantation. Bone Marrow Transplant., v.37, p.485-491, 2006.

SHAW, B.E.; MALDONADO, H.; MADRIGAL, J.A.; SMITH, C.; PETRONZELLI, F.; MAYOR, N.P.; POTTER, M.N.; BODMER, J.G.; MARSH, S.G. Polymorphisms in the TNFA gene promoter region show evidence of strong linkage disequilibrium with HLA and are associated with delayed neutrophil engraftment in unrelated donor hematopoietic stem cell transplantation. Tissue Antigens, v.63, p.401-411, 2004.

SOCIÉ, G.; LOISEAU, P.; TAMOUZA, R.; JANIN, A.; BUSSON, M.; GLUCKMAN, E.; CHARRON, D. Both genetic and clinical factors predict the development of graft-versus-host disease after allogeneic hematopoietic stem cell transplantation. Transplantation, v.72, p.699706, 2001.

TAKAHASHI, H.; FURUKAWA, T.; HASHIMOTO, S.; SUZUKI, N.; KUROHA, T.; YAMAZAKI, F.; INANO, K.; TAKAHASHI, M.; AIZAWA, Y.; KOIKE, T. Contribution of TNF-a and IL-10 gene polymorphisms to graft-versus-host disease following allo-hematopoietic stem cell transplantation. Bone Marrow Transplant., v.26, p.1317-1323, 2000. 
TAMBUR, A.R.; YANIV, I.; STEIN, J.; LAPIDOT, M.; SHABTAI, E.; KFIR, B.; KLEIN, T. Cytokine gene polymorphism in patients with graft-versus-host disease. Transplant. Proc., v.33, p.502-503, 2001.

TILG, H; DINARELLO, C.A.; MIER, J.W. IL-6 and APPs: Anti-inflammatory and immunosuppressive mediators. Immunol. Today, v.18, p.428-432, 1997.

TOMINAGA, K.; YOSHIMOTO, T.; TORIGOE, K.; KURIMOTO, M.; MATSUI, K.; HADA, T.; OKAMURA, H.; NAKANISHI, K. IL-12 synergizes with IL-18 or IL-1beta for IFN-gamma production from human T cells. Int. Immunol., v.2, p.151-160, 2000.

TREJAUT, J.A.; TSAI, Z.U.; LEE, H.L., Chen Z.X., Lin M. Cytokine gene polymorphisms in Taiwan. Tissue Antigens, v.64, p.492-499, 2004.

TSUNETO, L.T.; VISENTAINER, J.E.L.; CAVICHIOLI, A.G.; CONÇANI, A.P.; SILVA G.C.; SELL, A.M.; LIEBER, S.R.; PERSOLI, L.B.L.; MARQUES, S.B.D.; DE SOUZA, C.A. TNF-A (308G/A), IL-6 (1174C/G), IFN-Gamma (874T/A), IL-10 (1082 G/A, 819C/T, 592C/A), and TGF-B1 (+869T/C,+915G/C) genotype frequencies in the Caucasoid and Mulatto Brazilian populations. Tissue Antigens, v.66, p.569-569, 2005.

TURNER, D.M.; WILLIAMS, D.M.; SANKARAN, D.; LAZARUS, M.; SINNOTT, P.J.; HUTCHINSON, I.V. An investigation of polymorphism in the interleukin-10 gene promoter. Eur. J. Immunogenet., v.24, p.1-8, 1997.

UBOLDI DE CAPEI, M.U.; DAMETTO, E.; FASANO, M.E. ; RENDINE, S.; CURTONI, E. S. Genotyping for cytokine polymorphisms: allele frequencies in the Italian population. Eur. J. Immunogenet., v.30, p.5-10, 2003.
USHIO, S.; NAMBA, M.; OKURA, T.; HATTORI, K.; NUKADA, Y.; AKITA, K.; TANABE, F.; KONISHI, K.; MICALLEF, M.; FUJII, M.; TORIGOE, K.; TANIMOTO, T.; FUKUDA, S.; IKEDA, M.; OKAMURA, H.; KURIMOTO, M. Cloning of the cDNA for human IFN-gamma-inducing factor, expression in Escherichia coli, and studies on the biologic activities of the protein. J. Immunol., v.156, p.4274-4279, 1996.

VIEL, D.O.; TSUNETO, L.T.; SOSSAI, C.R.; LIEBER, S.R.; MARQUES, S.B.; VIGORITO, A.C.; ARANHA, F.J.; DE BRITO EID, K.A.; OLIVEIRA, G.B.; MIRANDA, E.C.; DE SOUZA, C.A.; VISENTAINER, J.E. IL2 and TNFA gene polymorphisms and the risk of graft-versus-host disease after allogeneic stem cell transplantation. Scand. J. Immunol., v.66, p.703-710, 2007.

VIZONI, S.L.; LIEBER, S.; DE SOUZA, C.A.; SELL, A.M.; VISENTAINER, J.E.L. Papel das citocinas na imunopatogênese da doença do enxerto contra o hospedeiro. Rev. Bras. Hematol. Hemoter., v.30, p.142-152, 2008.

WILSON, A.G.; SYMONS, J.A.; MCDOWELL, T.L.; MCDEVITT, H.O.; DUFF, G.W. Effects of a polymorphism in the human tumor necrosis factor alpha promoter on transcriptional activation. Proc. Natl. Acad. Sci. USA, v.94, p.3195-3199, 1997.

ZHAI, R.; LIU, G.; YANG, C.; HUANG, C.; WU, C.; CHRISTIANI, D.C. The $\mathrm{G}$ to C polymorphism at -174 of the interleukin-6 gene is rare in a Southern Chinese population. Pharmacogenetics, v.11, p.699-701, 2001.

Recebido para publicação em 20 de fevereiro de 2008 Aceito para publicação em 12 de agosto de 2008 